\title{
THE SCIENTIFIC WORK OF MAXIME BÔCHER.
}

BY PROFESSOR GEORGE D. BIRKHOFF.

With the recent death of Professor Maxime Bôcher at only fifty-one years of age American mathematics has suffered a heavy loss. Our task in the following pages is to review and appreciate his notable mathematical work.*

His researches cluster about Laplace's equation $\Delta u=0$, which is the very heart of modern analysis. Here one stands in natural contact with mathematical physics, the theory of linear differential equations both total and partial, the theory of functions of a complex variable, and thus directly or indirectly with a great part of mathematics.

His interest in the field of potential theory began in undergraduate days at Harvard University through courses given by Professors Byerly and B. O. Peirce. There is still on file at the Harvard library an undergraduate honor thesis entitled "A thesis on three systems of parabolic coördinates," written by him in 1888. Under the circumstances it was inevitable that he should use formal methods in dealing with his topic, but a purpose to penetrate further is found in the concluding sentences. No better opportunity for fulfilling such a purpose could have been granted than was given by his graduate work under Felix Klein at Göttingen (1888-1891).

In the lectures on Lamés functions which Klein delivered in the winter of 1889-1890 his point of departure was the cyclidic coördinate system of Darboux. This sytem of coordinates was known to be so general as to include nearly all of the many types of coördinates useful in potential theory, and Wangerin had shown (1875-1876) how solutions of Laplace's equation existed in the form of triple products, each factor being a function of one of the three cyclidic coördinates. After presenting this earlier work Klein extended his "oscillation theorem" for the case of elliptic coördinates (1881) to the more general cyclidic coördinates. By this means he was able to attack the problem of setting up a potential function taking on given values over the surface of a solid bounded by

* An account of his life and service by Professor Osgood will appear in a later number of the BULLETIN. 
six or fewer confocal cyclides. This function was given by a series of the triple "Lamé's" products discovered by Wangerin.

Klein also aimed to get at the various forms of series and integrals previously employed in potential theory as actual limiting cases, and thus to bring out the underlying unity in an extensive field of mathematics.

The task which Bôcher undertook was to carry through the program sketched by Klein. He did this admirably in his first mathematical paper "Ueber die Reihenentwickelungen der Potentialtheorie," which appeared in 1891 and which served both as a prize essay and as his doctor's dissertation at Göttingen.* But the space available was so brief that he was only able to outline results without giving their proofs.

One must look to his book with the same title, $\dagger$ published three years later, for an adequate treatment of the subject. Here is also to be found original work not outlined in his dissertation. It was characteristic that he did not call attention explicitly to the new advances although these formed his most important scientific work in the years 1891-1894. We turn now to a consideration of this book, which thus contains nearly all that he did before 1895 .

Besides giving the classification of all types of confocal cyclides in the real domain and of the corresponding Lamés products, as sketched by Klein, Bôcher determined to what extent the theorem of oscillation holds in the degenerate cases and found an interesting variety of possibilities.

The difficulties presented by these degenerate cases are decidedly greater than those of the general case when the singular points $e_{i}(i=1,2,3,4,5)$ of the Lamé's linear differential equation are regular with exponents $0,1 / 2$. A very simple degenerate case is that arising when two such points coincide in a single point and one of the two intervals $\left(m_{1}, m_{2}\right),\left(n_{1}, n_{2}\right)$ under consideration ends at this point. By an extension of Klein's geometric method, he proved that the theorem of oscillation fails to hold even here.

More specifically, the facts are as follows. In the general case the oscillation theorem states that for any choice of integers $m, n(m, n \geqq 0)$ there is a unique choice of the two ac-

* This paper appears as (2) in the chronological list of papers given at the end of the present article. Hereafter footnote references to papers will be made by number.

$\dagger(15)$. 
cessory parameters in the differential equation, yielding solutions $u_{1}, u_{2}$ such that $u_{1}$ vanishes at $m_{1}$ and $m_{2}$, and $m$ times for $m_{1}<x<m_{2}$, while $u_{2}$ vanishes at $n_{1}$ and $n_{2}$, and $n$ times for $n_{1}<x<n_{2}$. If now, for instance, $m_{1}$ lies at the double singular point $e_{1}=e_{2}$, while $m_{1}<m_{2}<e_{3}<e_{4}<n_{1}<n_{2}$ $<e_{5}$, there exist such solutions $u_{1}, u_{2}$ only if $n>r_{m}$ where $r_{m}$ is an integer increasing indefinitely with $m$. But, to compensate for this deficiency of solutions of the boundary value problem, Bôcher found it necessary to introduce solutions $u_{1 k}, u_{2 k}$ dependent on $n$ and a continuous real parameter $k$ such that $u_{1}$ vanishes at $m_{2}$ and infinitely often for $m_{1}<x$ $<m_{2}$ although remaining finite, while $u_{2}$ vanishes at $n_{1}$ and $n_{2}$, and $n$ times for $n_{1}<x<n_{2}$.

The corresponding expansion in Lamés products presents a remarkable form under these circumstances, for it is made up of a series and an integral component. In another case this type of expansion takes the form of an integral augmented by a finite number of complementary terms, as he had pointed out in an important paper "On some applications of Bessel's functions with pure imaginary index,"* published in 1892 in the Annals of Mathematics.

Although dealing satisfactorily with the oscillation theorem in the case specified above and other similar cases, Bôcher did not discuss adequately the case in which three or more singular points unite to form an irregular singular point. $\dagger$ Indeed it appears that he fell into an error of reasoning as follows. If the irregular point be taken at $t=+\infty$ the Lamés equation has the form

$$
\frac{d^{2} y}{d t^{2}}=\varphi y
$$

where in the case under consideration $\varphi$ has a limit $\varphi_{0} \neq 0$ as $t$ becomes infinite. The lemma which Bôcher then sought to prove $\ddagger$ was that there always exists a solution $y$ finite for $t \geqq T$ and not identically zero. His proof for the case $\varphi_{0}>0$ is essentially correct. Here he interpreted the equation above as the equation of motion of a particle distant $y$ from a point $O$ of its line of motion and repelled from it with a force $\varphi y$.

* (7). In passing, attention may also be called to a slightly earlier article (3) on Bessel's functions.

+ See $(15)$, p. 179 .

$\ddagger$ See (15), p. 177. 
The gist of the argument employed is that one can find an initial velocity of projection toward $O$ just sufficient to carry it into that point as a limiting position. This part of the lemma constitutes a very simple and interesting theorem concerning a special type of irregular point. In the case $\varphi_{0}<0$, however, using a similar dynamical interpretation, he argued* "we have infinitely many oscillations as we approach $t=+\infty$, and since the attractive force is not infinitely weak, the amplitudes of the oscillations remain finite." This argument appears insufficient although the lemma as stated for Lamé's equation is probably correct. $\dagger$ To satisfactorily complete the discussion it would seem to be necessary to call in the explicit analytic theory of the irregular singular point, since the corresponding theory of the regular singular point is required in the simpler cases. $\$$

In his book Bôcher considered the boundary problem under periodic conditions, when the interval between two adjacent singular points is taken an even number of times and is regarded as closed; this case arises, for example, when the solid in the potential problem is a complete ellipsoid. Here the function $\varphi$ in the linear differential equation above written is an even doubly periodic function with real period. By the aid of these properties of $\varphi$ he reduced the new boundary problem to one of the ordinary type.

Likewise in treating the roots of Lamés polynomials he made a distinct advance by extending the dynamical method of Stieltjes from the real axis to the complex plane. Thus he was able to prove that the roots of these polynomials lie within the triangle whose vertices are the three finite singular points of the corresponding Lamés equation.

Finally we may note that at the end of his book he obtained all Lamé's products satisfying the equation $\Delta u+k^{2} u=0$.

The determinative effect of the dissertation and book upon the direction of Bôcher's later researches was very great. In the first place he had used sphere geometry and the algebra of elementary divisors as essential tools in analysis; his resulting interest in the fundamental parts of geometry and algebra never subsided, and some of his research lies in these fields.

* (15), p. 178. The translation is not literal.

$\dagger$ In this connection see (7), p. 150, footnotes.

¥ Since the above was written Professor Osgood has disposed of the question at issue by elementary means. See his note in this number of the Bulletin. 
But, more important still, he was brought into contact with open mathematical questions. The most vital of these questions from the purely mathematical point of view was doubtless the very difficult analytical question of convergence and representation presented by the series of Lamé's products. This was the outstanding problem which Klein emphasized,* but to which Bôcher seems never to have given particular attention. Another more practical direction of effort was afforded by the task of giving rigorous and accessible form to the work of Sturm and Klein on the real solutions of ordinary linear differential equations and then going on further in this overlooked but attractive field of research. It was primarily to this task that he now turned.

In 1897 he published an article in the BuLLETIN $†$ showing the immediate usefulness of Sturm's theorems for fixing the distribution of the roots of Bessel's functions with real index. A year later in the same place he presented the fundamentals of Sturm's work in simplified rigorous form, and gave the first analytic proof of Klein's theorem of oscillation. $\ddagger$

Reference should also be made to his article on the boundary problems of ordinary differential equations which appeared in the German mathematical encyclopedia in 1900. This article together with his address on "Boundary problems in one dimension" before the Fifth International Congress of Mathematicians in 1912 give an excellent account of this field to the latter date.

Bôcher wrote a considerable number of other papers in this same field.§ Perhaps the most important of these are the three to which we will refer first and which appeared in the beginning volumes of the Transactions.

His paper "Application of a method of d'Alembert to the proof of Sturm's theorems of comparison" (1900) contained an elegant proof of what Bôcher had called the theorems of comparison. His method was entirely different from Sturm's, being based on the Riccati's resolvent equation, and was very simple.

In the second of these papers "On certain pairs of trans-

* See the concluding pages of his 1889-1890 lectures on Lamé's functions and his preface to Bôcher's book (15).

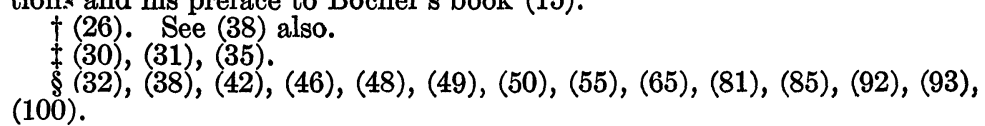


cendental functions whose roots separate each other"* (1901) his starting point was the linear differential equation

$$
y^{\prime \prime}+p y^{\prime}+q y=0,
$$

and a pair of linear forms in $y, y^{\prime}$,

$$
\Phi=\varphi_{2} y^{\prime}-\varphi_{1} y, \quad \Psi=\psi_{2} y^{\prime}-\psi_{1} y .
$$

These latter satisfy a "homogeneous Riccati's equation"

$$
\left(\varphi_{1} \psi_{2}-\varphi_{2} \psi_{1}\right)\left(\Phi^{\prime} \Psi-\Phi \Psi^{\prime}\right)+A \Phi^{2}+B \Phi \Psi+C \Psi^{2}=0,
$$

and Bôcher considered the relation of the roots of $\Phi, \Psi$.

$\mathrm{He}$ notes first that $\Phi, \Psi$ cannot vanish together unless $\varphi_{1} \psi_{2}-\varphi_{2} \psi_{1}=0$, for otherwise $y=y^{\prime}=0$. In order that $\Phi, \Psi$ cannot vanish together it is thus sufficient to assume $\varphi_{1} \psi_{2}-\varphi_{2} \psi_{1} \neq 0$. Also if $\Phi=0$, then $\Phi^{\prime} \neq 0$ if $C \neq 0$, by the above equation. A like remark holds for $\Psi$. Hence the roots of $\Phi, \Psi$ are simple if $A \neq 0, C \neq 0$.

Under these hypotheses between any pair of adjacent roots of $\Phi$ there must be a root of $\Psi$. For if $\Psi$ has no such root the homogeneous Riccati's equation at these roots shows that $\Phi^{\prime}$ has one and the same sign at both roots, which is impossible. Likewise between any pair of adjacent roots of $\Psi$ there must be a root of $\Phi$.

Hence the roots of $\Phi, \Psi$ separate each other if

$$
\varphi_{1} \psi_{2}-\varphi_{2} \psi_{1} \neq 0, A \neq 0, C \neq 0 .
$$

This is the third theorem of the paper. The sixth theorem gives similar conditions sufficient to ensure cyclical separation of the roots of three linear forms.

Here Bôcher not only achieved greater generality and simplicity than Sturm but, as I wish to point out, he has reached a maximum of generality.

For, let $y_{1}, y_{2}$ be any pair of linearly independent solutions yielding the values $\Phi_{1}, \Phi_{2}$ and $\Psi_{1}, \Psi_{2}$ of $\Phi$ and $\Psi$. Then

$$
\Phi=c_{1} \Phi_{1}+c_{2} \Phi_{2}, \quad \Psi=c_{1} \Psi_{1}+c_{2} \Psi_{2}
$$

are the general values of $\Phi, \Psi$. If $\Phi_{1}, \Phi_{2}$ are regarded as the homogeneous coordinates of a point $P$ in the projective line, $\Phi$ vanishes if $P$ coincides with $E \equiv\left(-c_{2}, c_{1}\right)$; similarly $\Psi$ vanishes if $Q=\left(\Psi_{1}, \Psi_{2}\right)$ coincides with the same point $E$.

* See also (100). 
Clearly the roots of $\Phi, \Psi$ will only be distinct for all values of $c_{1}, c_{2}$ if $\varphi_{1} \psi_{2}-\varphi_{2} \psi_{1} \neq 0$. Moreover, if these roots are to separate each other for all values of $c_{1}, c_{2}$, the points $P, Q$ must pass any point $E$ in alternation. This is only possible if $P, Q$ never reverse their direction of motion; in other words the Wronskians of $\Phi_{1}, \Phi_{2}$ and of $\Psi_{1}, \Psi_{2}$ must be of invariant signs. Taking into account the fact that $y_{1} y_{2}^{\prime}-y_{1}^{\prime} y_{2}$ is not zero, this gives precisely the conditions $A \neq 0, C \neq 0$.

This same geometric interpretation shows a similar generality in the other theorems.

Of like completeness is the third paper "On the real solutions of systems of two homogeneous linear differential equations of the first order" (1902), where he treated analogous questions and also derived comparison theorems.

It was a matter of primary interest with him to vary proofs of known theorems as well as to discover new theorems. An illustration in point is afforded by his treatment of the elementary separation theorem for the roots of linearly independent solutions $y_{1}, y_{2}$ of an ordinary linear differential equation of the second order.

Here he first gave a very brief proof* based on the function $y_{1} / y_{2}$ : if $y_{1}$ vanishes at $a$ and $b$ but not for $a<x<b$, while $y_{2}$ is not zero for $a \leqq x \leqq b$, then the derivative of $y_{1} / y_{2}$ is of one sign for $a<x<b$ since $y_{1} y_{2}{ }^{\prime}-y_{1}{ }^{\prime} y_{2} \neq 0$. This is impossible. By this argument and a like argument based on $y_{2} / y_{1}$ it follows that the roots of $y_{1}, y_{2}$ separate each other. In the same place $\dagger$ he isolates a geometric proof implicitly given by Klein depending on the fact that if $y_{1}, y_{2}$ be taken as homogeneous coördinates of a point in the projective line then $y_{1} y_{2}{ }^{\prime}-y_{1}^{\prime} y_{2} \neq 0$ is the condition that this point moves continually in one sense. Later he gave a second analytic proof based on the function

$$
\frac{y_{1}{ }^{\prime}}{y_{1}}-\frac{y_{2}{ }^{\prime}}{y_{2}}, \ddagger
$$

and also a second geometric proof* based on the vector $y_{1}+\sqrt{-1} y_{2}$ in the complex plane which will rotate continually in one sense if $y_{1} y_{2}^{\prime}-y_{2} y_{1}{ }^{\prime} \neq 0$.

* (26), p. 210.

$\dagger$ Footnote, p. 210.

$\ddagger(48)$.

$\S(99)$, pp. $46-47$. 
It was not easy for him to believe that the methods of Sturm were inadequate to deal with any particular boundary problem in one dimension. The problem for periodic conditions, which had been formulated by him in his encyclopedia article, was first successfully attacked by Mason in 1903-1904 by means of the calculus of variations. In a very interesting note published in 1905,* Bôcher showed that the principal result fell out immediately by the methods of Sturm, and that these methods were applicable under much more general conditions. Likewise in his address before the Fifth International Congress of Mathematicians alluded to above he noted that the equation

$$
\frac{d}{d x}\left(k \frac{d u}{d x}\right)+(\lambda g-l) u=0, \quad l<0,
$$

( $\lambda$ a parameter) comes directly under the case treated by Sturm after division by $|\lambda|$ even if $g$ changes sign. This simple remark disposed of the necessity of treating this case separately, as had been done earlier.

Bôcher was interested in all phases of the theory of ordinary linear differential equations with real independent variable. Having seen the gap in the theory of the regular singular point for real independent variable when the coefficients are not analytic, he proved that theorems analogous to those given by Fuchs in the complex domain are true. $\dagger$ It was necessary here to replace the power series treatment by a variation of the method of successive approximation which has been seen later to afford a new approach to the theory of the regular singular point in the complex domain.

He also did some work in the field of fundamental existence theorems for linear differential equations. $\ddagger$ He showed that it is sufficient to impose the condition of integrability (joined with other conditions) upon the coefficients in place of Peano's condition of continuity, $\S$ and thus advanced beyond Peano. Bôcher seems also to have been the first to prove that the solutions of a linear differential system are continuous functionals of the coefficients.

\footnotetext{
* $(65)$.

$+(37),(40),(41)$.

$\ddagger(32),(37),(56)$.

$\S(56)$, p. 311 .

II (56), p. 315 ; (55), p. 208.
} 
In 1901 he published a paper on "Green's functions in space of one dimension," in which he pointed out that the Green's function for the equation of Laplace in one dimension $y^{\prime \prime}=0$, exhibited by Burkhardt in 1894, might be extended to the general $n$th order ordinary linear differential equation with fairly general boundary conditions. These extended Green's functions have turned out to be of great importance. Later he returned to the subject of Green's functions with the most general linear boundary conditions and set up these functions for linear difference equations.* Also he extended the notion of adjoint boundary conditions to very general cases. $\dagger$

We have now referred briefly to the most important of his researches on ordinary linear differential equations with real independent variable. In this domain his best work is perhaps to be found. Directly springing from this field were his researches on linear dependence of functions of a single real variable $\ddagger$-an important topic which he was the first to isolate sufficiently from the field of linear differential equations.

His paper on "The roots of polynomials which satisfy certain linear differential equations of the second order" $\$$ lies in the field of ordinary linear differential equations with a complex variable. Here he generalizes further the extension of the method of Stieltjes which he had employed in dealing with Lamés polynomials.

The series arising in mathematical physics had been Bôcher's point of departure. Indeed it is the existence of these series which constitutes the main importance of the boundary value problems of linear differential equations. Nevertheless he gave special attention only to Fourier's series which he took up in an expository article in the Annals of Mathematics for 1906. Here he called attention to the remarkable phenomenon exhibited by a Fourier's series near a point of discontinuity, previously noted by Gibbs and called "Gibbs's phenomenon" by Bôcher who gave the first adequate treatment of it. T

His contributions to the theory of the harmonic function in two dimensions are elegant and distinctly important.

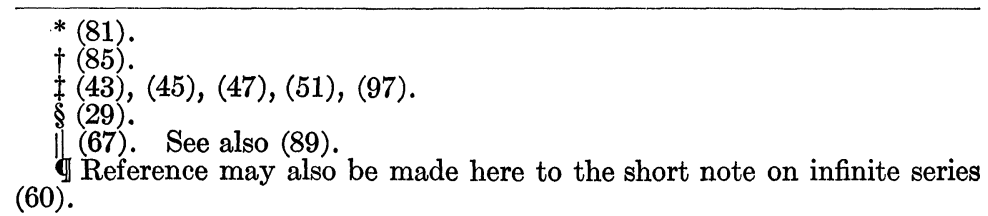


The first of these occurs incidentally in his paper "Gauss's third proof of the fundamental theorem of algebra."* It consists in a proof of the average value theorem by means of Gauss's theorem for the circle, which in polar coordinates $r, \varphi$ is

$$
\int_{0}^{2 \pi} \frac{\partial u}{\partial r} d \varphi=0
$$

Integrating with respect to $r$ from 0 to $a$ and reversing the order of integration, we get

$$
\int_{0}^{2 \pi}(u(a, \varphi)-u(0, \varphi)) d \varphi=0
$$

whence the average value theorem follows at once. This very neat proof was probably suggested by the artifice used by Gauss in his third proof of the fundamental theorem of algebra.

The "Note on Poisson's integral" (1898) gives a more natural interpretation of Poisson's integral than had been stated before. By the average value theorem a harmonic function is the average of its values on any circle with its center at the given point. He generalized this theorem in the spirit of the geometry of inversion and thus reached a visual interpretation of Poisson's integral which may be formulated as follows: The value of a harmonic function at any point within a circle is the average of its values as read by an observer at the point who turns with uniform angular velocity, if the rays of light to his eye take the form of circular arcs orthogonal to the given circle.

According to Riemann's program, the theory of harmonic functions requires a development independent of the theory of functions of a complex variable. In 1905 Bôcher demonstrated $\dagger$ that a harmonic function could not become infinite at a point unless it was of the form $C \log r+v$, where $C$ is a constant, $r$ is the distance from a variable point to the given point and $v$ is harmonic at that point. This theorem corresponds to the fundamental theorem in functions of a complex variable which states that if $f(z)$ becomes infinite at the isolated singular point $z=a$, then $f(z)$ is of the form $(z-a)^{-r} g(z)$ where $r$ is a positive integer and $g(z)$ is analytic and not zero

* (17), p. 206.

$\dagger(59)$. 
at $z=a$. He demonstrated further that a similar theorem holds for large classes of linear partial differential equations.

Another extremely interesting paper "On harmonic functions in two dimensions" appeared in 1906. Here he defines $u$ to be harmonic if it is single valued and continuous with continuous first partial derivatives and satisfies Gauss's theorem for every circle. If $u$ possessed continuous second partial derivatives also it would then follow at once by Green's theorem that $u$ is harmonic in the customary sense. But it is the merit of Bôcher's paper to have proved that $u$ is harmonic in the ordinary sense without further assumptions. On the basis of the definition made, the average value theorem is first deduced as outlined above. Also if $s^{\prime}, n^{\prime}$ are the new variables $s, n$ after an inversion (taking circles into circles) we have

$$
0=\int \frac{\partial u}{\partial n} d s=\int \frac{\partial u}{\partial n^{\prime}} d s^{\prime}
$$

along corresponding circles, since $d s^{\prime} / d n^{\prime}=d s / d n$ (the inversion being conformal). Thus $u$ is "harmonic" in the transformed plane also, so that the definition is invariant under inversion. Hence Poisson's integral formula, which comes from the average value theorem by inversion, also holds, and $u$ is harmonic in the ordinary sense.

$\mathrm{He}$ also determined the precise region of convergence of the real power series in $x, y$ for any harmonic function $u(x, y) .{ }^{*}$

In connection with his papers on harmonic functions in two dimensions it is natural to call to mind his early paper "On the differential equation $\Delta u+k^{2} u=0$ " (1893), which is taken in two dimensions. The " $u$-functions" so defined give a generalization of harmonic functions which he treated by means of the fact that $u(x, y) e^{k z}$ satisfies Laplace's equation in three dimensions. A similar method had been employed earlier by Klein.

Practically none of Bôcher's work lies directly in the field of functions of a complex variable. $\dagger$

We have still to consider his contributions in the fields of algebra and geometry. In the early paper on the fundamental theorem of algebra cited above he made clear how, by taking for granted a few theorems in functions of a complex variable,

* (74).

$\dagger$ See (78), however. 
an immediate proof could be given; and then he went on to show that by elimination of these theorems, the proof could be given a second more fundamental form and finally a third form due to Gauss and involving only distinctly elementary theorems. In a second paper* he simplified Gauss's proof very considerably by replacing Gauss's auxiliary function $z f^{\prime} / f$ by $1 / f$. Here $f=0$ is the given equation.

Here and elsewhere he succeeded in simplifying an apparently definitive proof. This kind of work was congenial to Bôcher, who believed that mathematics was capable of almost indefinite simplification, and that such simplification was of the highest consequence.

In the paper with the title "A problem in statics and its relation to certain algebraic invariants" (1904) he employed a dynamical method similar to his extension of the method of Stieltjes in order to develop an interpretation of the roots of covariants as the positions of equilibrium of particles in the complex plane. Thus if $f_{1}, f_{2}$ are polynomials of the same degree in the homogeneous variables $x_{1}, x_{2}$, the vanishing of their Jacobian determines the points of equilibrium in the field of force under the inverse first power law due to particles of "mass" 1 at the roots of $f_{1}$ and of "mass" -1 at the roots of $f_{2}$ in the $x_{1} / x_{2}$ plane.

We shall not refer to his geometrical papers $\dagger$ save to mention the one entitled "Einige Sätze über projective Spiegelung" (1893) in which he proves that conics in different planes may be projectively reflected into each other through a pair of lines in four ways, and also that the general collineation of space may be represented as the product of a rigid motion and a projective reflection through a pair of lines.

Besides this original research he undertook various more or less didactic articles with characteristic unselfishness. $\ddagger$ However, just as in the article on Fourier's series, matter of an original cast is nearly always present.

The same may be said of his books, $\S$ even of the most elementary. We have already considered his book on the series of potential theory. Of the others, the most significant are his Algebra, where a satisfactory exposition of the elementary

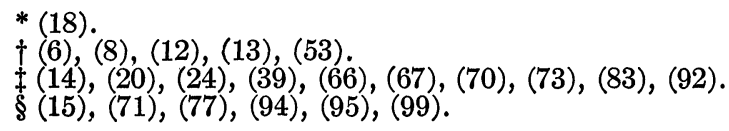


divisor theory is given, his Cambridge tract on integral equations," and his Paris 1913-14 lectures "Leçons sur les Méthodes de Sturm." In the last is given the first complete discussion of the convergence of the series used in the method of successive approximations. This furnishes another good instance of Bôcher's power to seize on important theorems which have been missed although near at hand. In concluding this brief survey it is worth while noting that a few of his papers are fairly popular in character. $\dagger$

In a recent one of these, "Mathématiques et mathématiciens Français" (1914), while speaking of the characteristics of American creative work in all fields (page 9), Bôcher says " $\mathrm{Ce}$ qu'il y a de plus caractéristique dans la meilleure production intellectuelle américaine, c'est la finesse et le contrôle voulu des moyens et des effets. La faute la plus commune dans ce que nous avons fait de mieux, ce n'est pas l'excès de force, mais plutôt son défaut" and later (page 10) "Ce que je viens de dire se rapporte aussi bien aux mathématiques qu'à toute autre branche de la production intellectuelle en Amérique." There can be no doubt that this characterization is applicable to his own mathematical production. His papers excel in simplicity and elegance, and nearly all of them treat subjects of great importance to marked advantage. The usefulness of his papers is exceptional, $\ddagger$

In amount and quality his production exceeds that of any American mathematician of earlier date in the field of pure mathematics.

Because of this fact and the weight he has added to our mathematical traditions in other ways, Maxime Bôcher will ever remain a memorable personality in American mathematics.

\section{List of BôcheR's WRITINGs.\|} 1888.

(1) The meteorological labors of Dove, Redfield and Esspy. American Meteorological Journal, vol. 5, No. 1, pp. 1-13, May.

* In connection with this, attention should be called to a short note on integral equations listed as (84) below.

$\dagger(1),(9),(11),(82),(90),(91)$. His first paper "On the meteorological labors of Dove, Redfield and Espy" was a youthful essay written about the time of his graduation from Harvard University.

$\ddagger$ This is brought out clearly in Professor Osgood's Lehrbuch der Funktionentheorie, vol. 1 .

\| Substanti ally as compiled by him. 
1891.

(2) Über die Reihenentwickelungen der Potentialtheorie. Gekrönte Preisschrift und Dissertation. Göttingen, Kästner. $4+66$ pp.

1892.

(3) On Bessel's functions of the second kind. Annals of Mathematics, vol. 6, No. 4, pp. 85-90, Jan.

(4) Pockels on the differential equation $\Delta u+k^{2} u=0$ [Review]. Annals of Mathematics, vol. 6, No. 4, pp. 90-92, Jan.

(5) Geometry not mathematics [Letter to editor]. Nation, vol. 54, No. 1390 , p. 131, Feb.

(6) On a nine-point conic. Annals of Mathematics, vol. 6, No. 5, p. 132, March.

(7) On some applications of Bessel's functions with pure imaginary index. Annals of Mathematics, vol. 6, No. 6, pp. 137-160, May.

(8) Note on the nine-point conic. Annals of Mathematics, vol. 6, No. 7, p. 178, June.

(9) Collineation as a mode of motion. Bulletin of the New York Mathematical Society, vol. 1, No. 10, pp. 225-231, July.

\section{3.}

(10) On the differential equation $\Delta u+k^{2} u=0$. American Journal of Mathematics, vol. 15, No. 1, pp. 78-83, Jan.

(11) A bit of mathematical history. Bulletin of the New York Mathematical Society, vol. 2, No. 5, pp. 107-109, Feb.

(12) Some propositions concerning the geometric representation of imaginaries. Annals of Mathematics, vol. 7, No. 3, pp. 70-72, March.

(13) Einige Sätze über projective Spiegelung. Mathematische Annalen, vol. 43 , No. 4, pv. 598-600.

(14) Chapter IX, Historical Summary, pp. 267-275. An Elementary Treatise on Fourier's Series and Spherical, Cylindrical and Ellipsoidal Harmonics. By W. E. Byerly. Boston, Ginn.

\section{4.}

(15) Über die Reihenentwickelungen der Potentialtheorie. Mit einem Vorwort von Felix Klein. Leipzig, Teubner, $8+258$ pp.

\section{5.}

(16) Hayward's Vector Algebra [Review]. Bulletin of the American Mathematical Society, ser. 2, vol. 1, No. 5, pp. 111-115, Feb.

(17) Gauss's third proof of the fundamental theorem of algebra. Bulletin of the American Mathematical Society, ser. 2, vol. 1, No. 8, pp. 205209, May.

(18) Simplification of Gauss's third proof that every algebraic equation has a root. American Journal of Mathemaiics, vol. 17, No. 3, pp. 266-268, July.

(19) General equation of the second degree [Set of formulas on a card]. Harvard University Press.

1896.

(20) On Cauchy's theorem concerning complex integrals. Bulletin of the American Mathematical Society, ser. 2, vol. 2, No. 5, pp. 146-149, Feb.

(21) Bessel's functions [Review]. Bulletin of the American Mathematical Society, ser. 2, vol. 2, No. 8, pp. 255-265, May. 
(22) Linear differential equations and their applications. [Report by T. S. Fiske of a lecture at the Buffalo Colloquium]. Bulletin of the American Mathematical Society, ser. 2, vol. 3, No. 2, pp. 52-55, Nov.

(23) Heffter's Linear Differential Equations [Review]. Bulletin of the American Mathematical Society, ser. 2, vol. 3, No. 2, pp. 86-92, Nov.

(24) Regular points of linear differential equations of the second order. Cambridge, Harvard University Press, $23 \mathrm{pp}$.

\section{$189 \%$.}

(25) Schlesinger's Linear Differential Equations [Review]. Bulletin of the American Mathematical Society, ser. 2, vol. 3, No. 4, pp. 146-153, Jan.

(26) On certain methods of Sturm and their application to the roots of Bessel's functions. Bulletin of the American Mathematical Society, ser. 2, vol. 3, No. 6, pp. 205-213, March.

(27) Review of Bailey and Woods: Plane and Solid Analytic Geometry. Bulletin of the American Mathematical Society, ser. 2, vol. 3, No. 9, pp. 351-352, June.

1898.

(28) Examples of the construction of Riemann's surfaces for the inverse of rational functions by the method of conformal representation. By C. L. Bouton with an introduction by Maxime Bôcher. Annals of Mathematics, vol. 12, No. 1, pp. 1-26, Feb.

(29) The roots of polynomials which satisfy certain linear differential equations of the second order. Bulletin of the American Mathematical Society, ser. 2, vol. 4, No. 6, pp. 256-258, March.

(30) The theorems of oscillation of Sturm and Klein (first paper). Bulletin of the American Mathematical Society, ser. 2, vol. 4, No. 7, pp. 295313, April.

(31) The theorems of oscillation of Sturm and Klein (second paper). Bulletin of the American Mathematical Society, ser. 2, vol. 4, No. 8, pp. 365-376, May.

(32) Note on some points in the theory of linear differential equations. Annals of Mathematics, vol. 12, No. 2, pp. 45-53, May.

(33) Note on Poisson's integral, Bulletin of the American Mathematical Society, ser. 2, vol. 4, No. 9, pp. 424-426, June.

(34) Niewenglowski's Geometry [Review]. Bulletin of the American Mathematical Society, ser. 2, vol. 4, No. 9, pp. 448-452, June.

(35) The theorems of oscillation of Sturm and Klein (third paper). Bulletin of the American Mathematical Society, ser. 2, vol. 5, No. 1, pp. 22-43, Oct.

\section{9.}

(36) Burkhardt's Theory of Functions [Review]. Bulletin of the American Mathematical Society, ser. 2, vol. 5, No. 4, pp. 181-185, Jan.

(37) On singular points of linear differential equations with real coefficients. Bulletin of the American Mathematical Society, ser. 2, vol. 5, No. 6, pp. 275-281, March.

(38) An elementary proof that Bessel's functions of the zeroth order have an infinite number of real roots. Bulletin of the American Mathematical Society, ser. 2, vol. 5, No. 8, pp. 385-388, May.

(39) Examples in the theory of functions. Annals of Mathematics, ser. 2, vol. 1 , No. 1, pp. 37-40, Oct.

1900.

(40) On regular singular points of linear differential equations of the second order whose coefficients are not necessarily analytic. Transactions of the American Mathematical Society, vol. 1, No. 1, pp. 40-52, Jan.; also No. 4, p. 507, Oct. 
(41) Some theorems concerning linear differential equations of the second order. Bulletin of the American Mathematical Society, ser. 2, vol. 6, No. 7, pp. 279-280; April.

(42) Application of a method of d'Alembert to the proof of Sturm's theorems of comparison. Transactions of the American Mathematical Society, vol. 1, No. 4, pp. 414-420, Oct.

(43) On linear dependence of functions of one variable. Bulletin of the American Mathematical Society, ser. 2, vol. 7, No. 3, pp. 120-121, Dec.

(44) Randwertaufgaben bei gewöhnlichen Differentialgleichungen. Encyklopädie der mathematischen Wissenschaften, II A 7a, pp. 437463, Leipzig, Teubner.

1901.

(45) The theory of linear dependence. Annals of Mathematics, ser. 2, vol. 2, No. 2, pp. 81-96, Jan.

(46) Green's functions in space of one dimension. Bulletin of the American Matherratical Society, ser. 2, vol. 7, No. 7, pp. 297-299, April.

(47) Certain cases in which the vanishing of the Wronskian is a sufficient condition for linear dependence. Transactions of the American Mathematical Society, vol. 2, No. 2, pp. 139-149, April.

(48) An elementary proof of a theorem of Sturm. Transactions of the American Mathematical Society, vol. 2, No. 2, pp. 150-151, April.

(49) Non-oscillatory linear differential equations of the second order. Bulletin of the American Mathematical Society, ser. 2, vol. 7, No. 8, pp. 333-340, May.

(50) On certain pairs of transcendental functions whose roots separate each other. Transactions of the American Mathematical Society, vol. 2, No. 4, pp. 428-436, Oct.

(51) On Wronskians of functions of a real variable. Bulletin of the American, Mathernatical Society, ser. 2, vol. 8, No. 2, pp. 53-63, Nov.

(52) Picard's Traité d'Analyse [Review]. Bulletin of the American Mathematical Society, ser. 2, vol. 8, No. 3, pp. 124-128, Dec.

\section{2.}

(53) Some applications of the method of abridged notation. Annals of Mathematics, ser. 2, vol. 3, No. 2, pp. 45-54, Jan.

(54) Review of Schlesinger: Einführung in die Theorie der Differentialgleichungen mit einer unabhängigen Variabeln. Bulletin of the American Mathematical Society, ser. 2, vol. 8, No. 4, pp. 168-169, Jan.

(55) On the real solutions of two homogeneous linear differential equations of the first order. Transactions of the American Mathematical Society, vol. 3, No. 2, pp. 196-215, April.

(56) On systems of linear differential equations of the first order, American Journal of Mathematics, vol. 24, No. 4, pp. 311-318, Oct.

(57) Review of Gauss' Wissenschaftliches Tagebuch. Bulletin of the American Mathematical Society, ser. 2, vol. 9, No. 2, pp. 125-126, Nov.

1908.

(58) The Elements of Plane Analytic Geometry. By George R. Briggs. Revised and enlarged by Maxime Bôcher. New York, Wiley, $4+$ $191 \mathrm{p}$.

(59) Singular points of functions which satisfy partial differential equations of the elliptic type. Bulletin of the American Mathematical Society, ser. 2, vol. 9, No. 9, pp. 455-465, June. 
(60) On the uniformity of the convergence of certain absolutely convergent series. Annals of Mathematics, ser. 2, vol. 4, No. 4, pp. 159160 , July.

$$
1904 .
$$

(61) Contribution to Sprechsaal für die Encyklopädie der Mathematischen Wissenschaften. Archiv der Mathematik und Physik, vol. 7, No. 3, p. 181, Feb.

(62) The fundamental conceptions and methods of mathematics. Address delivered before the Department of Mathematics of the International Congress of Arts and Science, St. Louis, Sept. 20, 1904. Bulletin of the American Mathematical Society, ser. 2, vol. 11, No. 3, pp. 115-135, Dec. Also in Congress of Arts and Science Universal Exposition, St. Louis, 1904, vol. 1. Boston, Houghton and Mifflin, 1905, pp. 456-473.

(63) A problem in statics and its relation to certain algebraic invariants. Proceedings of the American Academy of Arts and Sciences, vol. 40, No. 11 , pp. 469-484, Dec.

1905.

(64) Linear differential equations with discontinuous coefficients. Annals of Mathematics, ser. 2, vol. 6, No. 3, pp. 97-111 (49-63), April.

(65) Sur les équations différentielles linéaires du second ordre à solution périodique. Comptes Rendus de l'Académie des Sciences, vol. 140, No. 14, pp. 928-931, April.

(66) A problem in analytic geometry with a moral. Annals of Mathematics, ser. 2, vol. 7, No. 1, pp. 44-48, Oct.

1906.

(67) Introduction to the theory of Fourier's series. Annals of Malhematics, vol. 7, No. 2, and No. 3, pp. 81-152, Jan. and April.

(68) On harmonic functions in two dimensions. Proceedings of the Amsrican Academy of Arts and Sciences, vol. 41, No. 26, pp. 577-583, March.

(69) Review of Picard: Sur le Développement de l'Analyse, etc. Science, n. s., vol. 23, No. 598, p. 912, June.

(70) Another proof of the theorem concerning artificial singularities. Annals of Mathematics, ser. 2, vol. 7, No. 4, pp. 163-164, July.

$190 \%$.

(71) Introduction to Higher Algebra. By Maxime Bôcher. Prepared for publication with the cooperation of E. P. R. Duval. New York, Macmillan, $11+321$ pp.*

1908.

(72) Review of Bromwich: Quadratic Forms and their Classification by Means of Invariant Factors. Bulletin of the American Mathematical Society, ser. 2, vol. 14, No. 4, pp. 194-195, Jan.

(73) On the small forced vibrations of systems with one degree of freedom. Annals of Mathematics, ser. 2, vol. 10, No. 1, pp. 1-8, Oct.

1909.

(74) On the regions of convergence of power-series which represent twodimensional harmonic functions. Transactions of the American Mathematical Society, vol. 10, No. 2, pp. 271-278, April.

* A German translation appeared in 1909: Einführung in die höhere Algebra. Deutsch von Hans Beck. Mit einem Geleitwort von Eduard Study. Leipzig, Teubner, $12+348$ pp. 
(75) Review of Runge: Analytische Geometrie der Ebene. Bulletin of the American Mathematical Society, ser. 2, vol. 16, No. 1, pp. 30-33, Oct.

(76) Review of d'Adhémar: Exercices et Leçons d'Analyse. Bulletin of the American Mathematical Society, ser. 2, vol. 16, No. 2, pp. 87-88, Nov.

(77) An introduction to the study of integral equations. Cambridge Tracts in Mathematics and Mathematical Physics, No. 10, Cambridge, England, University Press, 72 pp.*

1910.

(78) On semi-analytic functions of two variables. Annals of Mathematics, ser. 2, vol. 12 , No. 1, pp. 18-26, Oct.

(79) Kowalewski's Determinants [Review]. Bulletin of the American Mathematical Society, ser. 2, vol. 18, No. 3, pp. 120-140, Dec.

\section{1.}

(80) The published and unpublished work of Charles Sturm on algebraic and differential equations. Presidential address delivered before the American Mathematical Society, April 28, 1911. Bulletin of the American Mathematical Society, ser. 2, vol. 18, No. 1, pp. 1-18, Oct.

(81) Boundary problems and Green's functions for linear differential and difference equations, Annals of Mathematics, ser. 2, vol. 13, No. 2, pp. 71-88, Dec.

(82) Graduate work in mathematics in universities and in other institutions of like grade in the United States. General report. United States Bureau of Education Bulletin, No.6, pp. 7-20. Also in Bulletin of the American Mathematical Society, ser. 2, vol. 18, No. 3, pp. 122-137, Dec.

1912.

(83) On linear equations with an infinite number of variables. By Maxime Bôcher and Louis Brand. Annals of Mathematrcs, ser. 2, vol. 13, No. 4, pp. 167-186, June.

(84) A simple proof of a fundamental theorem in the theory of integral equations. Annals of Mathematics, ser. 2, vol. 14, No. 2, pp. 8485 , Dec.

$$
1913 .
$$

(85) Applications and generalizations of the conception of adjoint systems, Transactions of the American Matherratical Society, vol. 14, No. 4, pp. 403-420, Oct.

(86) Doctorates conferred by American universities [Letter to the editor], Science, n. s., vol. 38 , No. 981 , p. 546, Oct.

(87) Boundary problems in one dimension [A lecture delivered Aug. 27, 1912]. Proceedings of the Fifth International Congress of Mathematicians, Cambridge, England, University Press, vol. 1, pp. 163-195.

$$
1914 .
$$

(88) The infinite regions of various geometries. Bulletin of the American Mathematical Society, ser. 2, vol. 20, No. 4, pp. 185-200, Jan. $\dagger$

(89) On Gibbs's phenomenon. Journal für die reine und angewandte Mathematik, vol. 144, No. 1, pp. 41-47, Jan.

* A second edition appeared in 1914 .

† See vol. 22, (1915) No. 1, p. 40, Oct. 
(90) Mathématiques et mathématiciens français. Rerue Internationale de l'Enseignement, vol. 67, No. 1, pp. 20-31, Jan.

(91) Charles Sturm et les mathématiques modernes. Revue du Mois, vol. 17, No. 97, pp. 88-104, Jan.

(92) On a small variation which renders a linear differential system incompatible. Bulletin of the American Mathematical Society, ser. 2, vol. 21, No. 1, pp. 1-6, Oct.

(93) The smallest characteristic number in a certain exceptional case. Bulletin of the American Mathematical Society, ser. 2, vol. 21, No. 1, pp. 66-99, Oct.

1915.

(94) Trigonometry with the theory and use of logarithms. By Maxime Bôcher and H. D. Gaylord, New York, Holt, $9+142 \mathrm{pp}$.

(95) Plane analytic geometry with introductory chapters on the differential calculus. New York, Holt, $13+235 \mathrm{pp}$.

1916.

(96) Review of Gibb: A Course in Interpolation etc. and Carse and Shearer: A Course in Fourier's Analysis etc. Bulletin of the American Mathematical Society, ser. 2, vol. 22, No. 7, pp. 359-361, April.

(97) On the Wronskian test for linear dependence, Annals of Mathematics, ser. 2 , vol. 17 , No. 4, pp. 167-168, June.

(98) Syllabus of a Brief Course in Solid Analytic Geometry. Lancaster, New Era Press, 10 p.

(99) Leçons sur les méthodes de Sturm dans la théorie des équations différentielles linéaires et leurs développements modernes. Professées à la Sorbonne en 1913-14. Recueillies et rédigées par G. Julia. Paris, Gauthier-Villars, $6+118$ pp.

$191 \%$.

(100) Note supplementary to the paper "On certain pairs of transcendental functions whose roots separate each other." Transactions of the American Mathematical Society, vol. 18, No. 4, pp. 519-521, Oct.

\section{8}

(101) Concerning direction cosines and Hesse's normal form. American Mathematical Monthly, vol. 25, No. 7, pp. 308-310, Sept. 